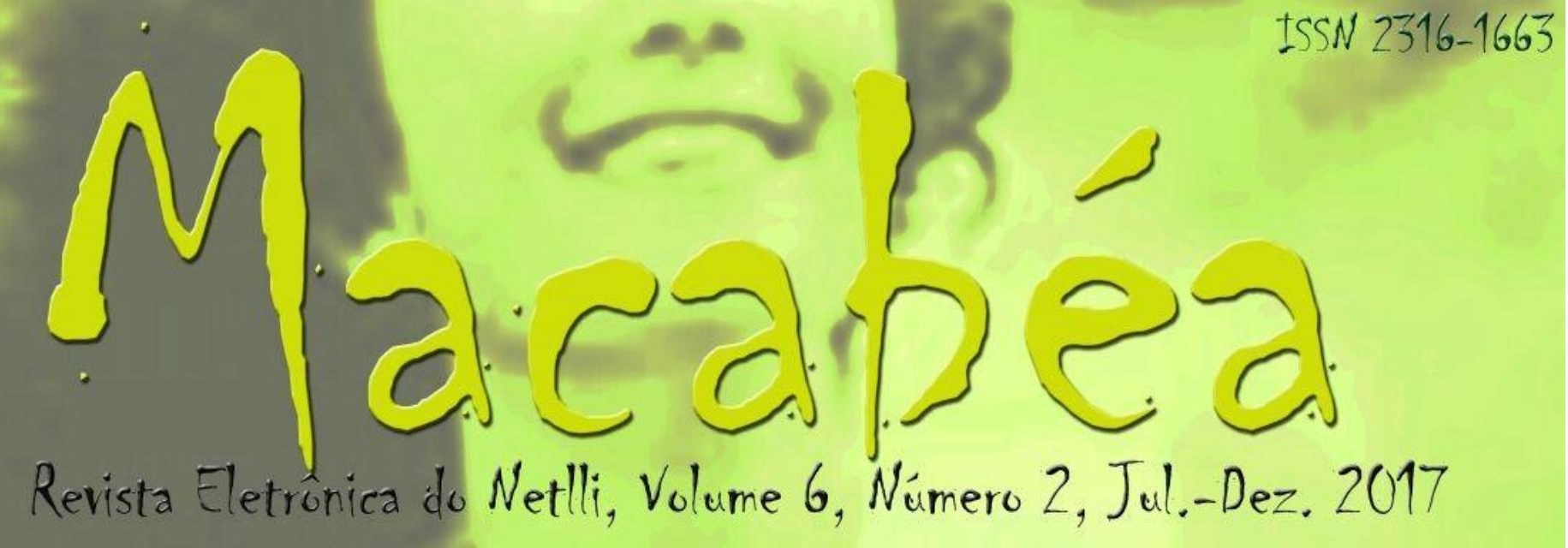

\title{
HISTÓRIAS DA PROSTITUIÇÃO: LEITURAS DE ENTRETENIMENTO NO BRASIL OITOCENTISTA
}

\section{STORIES OF PROSTITUTION: READINGS OF ENTERTAINMENT IN NINETEENTH-CENTURY BRAZIL}

\section{Renata Ferreira VIEIRA Universidade Estadual do Rio de Janeiro (UERJ)}

\section{Abstract}

Censored by parents and conservative critics, stories about prostitutes have always been "forbidden" readings that, in addition to stimulating the book trade over the years, offered readers entertainment through the "euphoria and sensations" caused by the stuffed works with obscene plots and / or sexual insinuations. It is in this perception of reading, in nineteenth-century Brazil, who were the novels about the "women of life" like Lucíola (1862), the Brazilian writer José de Alencar (1829-1877), 
and Nana (1880), the French writer Émile Zola (1840-1902). Affiliated, respectively, with romantic and naturalistic esthetics, Luciola and Nana fictionalize the live of two young prostitutes in a nineteenth-century patriarchal society. In order to understand how these novels were appropriated as "entertainment literature" by the reading public of the time, this article will investigate the trajectory of publication, circulation and reception of these works through the theoretical assumptions of the history of books and reading (CHARTIER, 1990 ).

\section{Resumo}

Censuradas pelos pais de família e críticos conservadores, as histórias sobre prostitutas sempre foram leituras "proibidas" que, além de estimularem o comércio livreiro ao longo dos anos, ofereciam entretenimento aos leitores por meio das "euforias e sensações" causadas pelas obras recheadas com enredos obscenos e/ou insinuações sexuais. É nessa percepção de leitura, no Brasil oitocentista, que se encontravam os romances sobre as "mulheres da vida" como Lucíola (1862), do escritor brasileiro José de Alencar (1829-1877), e Nana (1880), do escritor francês Émile Zola (1840-1902). Filiados, respectivamente, às estéticas romântica e naturalista, Lucíola e Nana ficcionalizam a vida de duas prostitutas jovens numa sociedade patriarcal do século XIX. Com objetivo de compreender como esses romances eram apropriados como "literatura de entretenimento" pelo público leitor da época, este trabalho investigará a trajetória de publicação, circulação e recepção dessas obras por meio dos pressupostos teóricos da história do livro e da leitura (CHARTIER, 1990).

Entradas para indexação

KEYWORDS: Readings. Prostitutes. Entertainment.

PALAVRAS-CHAVE: Leituras. Prostitutas. Entretenimento.

\section{Texto integral}

\section{Introdução}

Além de ser a atividade do leitor profissional, como o escritor, o livreiroeditor e o crítico literário, a leitura era também o puro divertimento de vários leitores comuns no Brasil oitocentista. Da década de 1880 a 1890, o ramo livreiro tornava-se um negócio promissor aos diversos comerciantes, especialmente os do Rio de Janeiro onde o mercado editorial expandia rapidamente (EL FAR, 2004). Nos catálogos das livrarias havia uma gama de livros com preços populares, como 
os romances sobre prostitutas, os volumes mais vendidos pelo comércio livreiro. Nos anúncios, os romances sobre as "mulheres da vida", como Lucíola (1862), do escritor brasileiro José de Alencar (1829-1877), e Nana (1880), do escritor francês Émile Zola (1840-1902), recebiam uma atenção especial dos livreiros-editores. Eles percebiam que os livros de teor "picante" eram a diversão preferida dos leitores por causa das histórias recheadas com enredos obscenos e/ou insinuações sexuais. Com objetivo de compreender como Lucíola e Nana eram apropriados como "literatura de entretenimento" pelo público leitor da época, farei uma breve investigação sobre a trajetória de publicação, circulação e recepção desses romances, por meio dos pressupostos teóricos da história do livro e da leitura (CHARTIER, 1990). Para seguir os vestígios dessa trajetória, pesquisarei o Acervo da Hemeroteca Digital Brasileira da Biblioteca Nacional para levantar informações sobre a primeira circulação desses dois livros, acrescido dos estudos críticos que aparecem na bibliografia.

\section{Lucíola}

Quando o romance Lucíola foi publicado, em 1862, pela Tipografia Francesa de Frederico Arfvedson, o mercado editorial não se encontrava no auge do comércio livreiro, porém era um negócio atrativo devido ao aumento do público leitor no Rio de Janeiro (EL FAR, 2004). "Um dos primeiros estabelecimentos da cidade, montado com prelos mecânico e de mão", a Tipografia Francesa realizava qualquer impressão, oferecendo serviços "por preços os mais módicos que era possível" Uornal do Comércio, 26/02/1863, p.4). Na distribuição dos romances publicados pela casa, a Tipografia Francesa efetivava parcerias com diversas livrarias de preços populares no país. Na ocasião da primeira edição de Lucíola, o romance era vendido por $2 \$ 000$ (dois mil réis). Em 1870, o editor francês Baptiste Louis Garnier (1823-1893) contratou José de Alencar e passou a editar seus romances, entre eles Lucíola que era vendido em volume encadernado no valor de $3 \$ 000$ (três mil réis). 0 contrato de José de Alencar com a Livraria Garnier indicava a popularidade do escritor no cenário literário nacional. Todos sabiam que o editor Garnier não publicava livro de escritor estreante ou de pouco prestígio, somente, as obras de autores consagrados, como Machado de Assis (1839-1908) e Aluísio Azevedo (1857-1913).

Lucíola foi o quarto romance de José de Alencar. A história é sobre a jovem Maria da Glória, que ingressa na vida de prostituição para conseguir dinheiro para tratar da família doente de febre amarela. Expulsa de casa pelo pai, Maria da Glória (sob o nome de Lúcia) torna-se a cortesã "mais bonita do Rio de Janeiro e também a mais caprichosa e excêntrica" (ALENCAR, 2007, p.18). 0 romance, organizado em forma epistolar, reúne as cartas do Paulo Silva endereçadas à senhora G.M, um dos pseudônimos de Alencar. 0 conteúdo das cartas era as recordações do relacionamento amoroso de Paulo com Lúcia. A destinatária era uma distinta mulher da sociedade fluminense que, na narrativa, representa dois papéis: confidente e editora da "história imoral" de Paulo (ALENCAR, 2007, p.30). 
Encarregada de reunir as cartas e transformá-las em livro, a senhora G.M deu a obra o título de "Lucíola, nome de um inseto que brilha de uma luz tão viva na treva e na beira dos charcos". A escolha do nome devia ao "perfil que o Paulo desenhou com tanto esmero [nas cartas]: uma mulher que no abismo da perdição conservava a pureza da alma" (ALENCAR, 1862, p.4). Além dessas representações, a senhora G.M simbolizava o grupo social para o qual o Paulo desejava contar suas "recordações prazerosas", a sociedade hipócrita dos "severos moralistas" da segunda metade do século XIX (ALENCAR, 2007, p.30).

Não encontrei nos periódicos de 1862 artigos ou comentários sobre Lucíola. A fria recepção do livro na imprensa, no primeiro momento de sua circulação, era o motivo de queixa de Alencar. Segundo o escritor, ele não tinha nenhuma colaboração dos críticos para a divulgação dos seus romances (BEZERRA, 2012). Em 1863, os poucos comentários sobre Lucíola eram associados à outra obra de Alencar, a peça teatral As asas de um anjo, encenada em 1858 no Ginásio Dramático do Rio de Janeiro. Após três apresentações, a peça saiu de cartaz porque foi censurada pela polícia por encenar conteúdo imoral ${ }^{1}$. Assim como As asas de um anjo, o romance A Dama das Camélias (1848), do escritor francês Alexandre Dumas (1824-1895), foi objeto de associação a Lucíola. Os dois livros abordam o amor sincero (e correspondido) de duas prostitutas aos seus amantes, que preferem renunciar o amor deles para preservar a hipócrita moral burguesa. Para o colunista da seção 'Literatura', do Correio Paulistano, Lucíola "é [era] uma cópia mais ou menos feliz da Dama das Camélias; é [era] o vício contado desgraçadamente por uma elegante pena" (Correio Paulistano, 03/05/1863, p.2).

Se Lucíola era cópia de Dama das Camélias ou continuação dramática de $A s$ asas de um anjo para alguns colunistas, para o crítico T. A. Pereira, do Correio Paulistano, o romance de Alencar era um exemplo do realismo casto sobre as "mulheres caídas" nas desventuras da vida. Segundo T. A. Pereira, em Lucíola não havia a "priapeia ou realismo libertino" do escritor francês Gustave Flaubert (1821-1880), autor do romance Madame Bovary (1857), cuja protagonista "tinha sede de lubricidade convulsiva" (Correio Paulistano, 27/11/1863, p.2). Na leitura do crítico, Lúcia era digna de adoração. A protagonista "não era prostituta, apenas caída, tinha pecado sem intenção", foi levada ao "vício carnal" pela força das circunstâncias. Para o crítico, Lucíola era um romance edificante porque retratava a virtude de uma mulher que no "seio da perdição" não perdeu a nobreza do seu caráter (Correio Paulistano, 27/11/1863, p.2). 0 crítico do Correio Paulistano (como leitor culto) buscava o aspecto moral nos romances sobre prostitutas para justificar o prazer da sua leitura. Desse modo, ele sugeria que a maioria dos leitores cultos quando se apropria dos "livros imorais" era para desfrutar (somente) da qualidade das lições morais extraídas da leitura.

Na Imprensa Acadêmica de 1864, o crítico Machado de Assis (outro leitor culto) - sob o pseudônimo de Sileno - expandia a recepção de Lucíola, considerando o modo de ler dos leitores comuns. Nesse jornal, Machado fazia algumas revelações sobre a circulação do livro, ao compará-lo com Diva, outro romance de José de Alencar. Machado relembrou como o público leitor não foi indiferente a Lucíola, apesar do escasso comentário da impressa: "Todos se lembram do barulho que fez Lucíola. Terá este [Diva] a mesma fortuna? Ouso duvidar. Lucíola tinha mais condições de popularidade". Para Machado, Diva era o 
típico romance pudico, e "para um público afeito a outro gênero isto já era um elemento de mau êxito" (Apud MAGALHÃES JÚNIOR, 1977, p.163). Na percepção de Machado, Lucíola tinha seu público específico, os "afeitos" às páginas "picantes" do romance, como as cenas do belo corpo de Lúcia e das "expansões de sensualidade" entre os amantes (ALENCAR, 2007, p.99). Percebendo Lucíola desse modo, Machado indicava que os romances sobre prostitutas eram as obras mais populares. Os leitores buscavam esses livros sem a intenção de obter instrução moral, mas a de se divertir por meio das sensações eróticas despertadas da leitura.

Em 1864, o editorial da Semana Ilustrada anunciava o lançamento de Diva e reforçava o potencial de Lucíola para literatura de entretenimento. Num paralelo entre os dois romances de Alencar, o jornal mencionava como foi "despercebido o aparecimento de Lucíola no meio literário" (Semana Ilustrada, 17/04/1864, p.1398). Com bom humor, a Semana Ilustrada afirmava que o silêncio da imprensa devia à recomendação do autor, que advertia, na primeira página do livro, para que o romance não fosse lido pelas netas de suas avós. A Semana alegava que a "imprensa periódica, que é neta paterna do falecido Sr. Gutenberg, entendeu que também com ela se entendia a recomendação do autor" (Semana Ilustrada, 17/04/1864, p.1398). Para Semana, Lucíola, com seu "texto vivaz e cintilante", era um "fruto proibido" saboroso e admirável. 0 aviso do autor só serviu para "excitar a curiosidade e o aplauso de todos os profanos, que ousaram desvirginar-se com a leitura desse formoso monstro literário" (Semana Ilustrada, 17/04/1864, p.1398). A declaração da Semana Ilustrada trazia à luz o sucesso de público de Lucíola. 0 romance atraía a "fome" dos leitores de histórias transgressoras, que se deleitavam com a sensualidade de Lúcia semelhante "às das cortesãs gregas ou às das messalinas romanas" (ALENCAR, 2007, p.46).

De acordo com a pesquisa, a imprensa registrou a circulação e a recepção de Lucíola até o ano de 1883, vinte e um anos após a publicação do romance. Nesses registros, os críticos conservadores afirmavam que o romance, "ao publicar-se, causou um escândalo", conquistando logo a "fama de livro imoral". (O País, 14/02/1883, p.1). Para os críticos, Lucíola teria vida longa na cena literária, pois "os amantes de livros obscenos" comprariam, por muito tempo, o afamado romance de "páginas lascivas" (O País, 14/02/1883, p.1). Além do apreço do público leitor, Lucíola conquistou também os "aplausos das filhas inocentes no teatro", que se emocionavam com a "desgraçada sorte" de Lúcia ( $O$ País, 14/02/1883, p.1). A censura dos críticos e das "prudentes mães de família, que escondiam o romance das suas filhas para que elas não perdessem a pureza virginal", não impediu o êxito de Lucíola na literatura de entretenimento, que oferecia aos seus leitores o prazer de ler as histórias de prostitutas no século XIX (O País, 14/02/1883, p.1).

\section{Nana}

Em março de 1880, a imprensa brasileira noticiava que o jornal parisiense Le Voltaire tinha publicado o último capítulo do folhetim Nana, do "ruidoso chefe da escola naturalista" Émile Zola (Gazeta de Notícias, 07/03/1880, p.1). 0 folhetim foi publicado de 16 de outubro de 1879 a 5 de fevereiro de 1880, aumentando 
consideravelmente os lucros do jornal, como também a polêmica em torno do nome de Zola. Famoso pelo "barulho" causado pela história da jovem prostituta, Zola despertou o interesse de Georges Charpentier (1846 - 1905), conhecido como o editor de naturalistas (SILVA, 1999), entre eles Edmond de Goncourt (1822 1896) e Alphonse Daudet (1840 - 1897). Charpentier, empolgado com a popularidade de Zola, contratou o escritor, lançando o romance Nana com 55 mil volumes encomendados pelos livreiros (Gazeta de Notícias, 07/03/1880, p.1). No Brasil, o mercado editorial não tardou a traduzir o "célebre romance de Zola", que era vendido por $2 \$$ (dois mil réis) nas edições baratas e $4 \$ 000$ (quatro mil réis) nas luxuosas (Gazeta da Tarde, 02/08/1880, p.2).

Nana é o nono livro de uma coleção de vinte romances chamada Les Rougon-Macquart (1871), que descreve a História Social das cinco gerações dessa mesma família. 0 livro é sobre a vida de Anna Teresa Coupeau (apelido Nana), filha de uma lavadeira e de um pai alcoólatra, que moravam na "enlameada Rue de la Goutte d'Or", situada ao norte da capital francesa (ZOLA, 2002, p.291). Aos 18 anos, Nana torna-se a cortesã mais célebre de Paris entre os anos de 1869 e 1870, a fase final do Segundo Império francês (1852 - 1870). Sua fama começou no bordel Théâtre des Variétés, onde conheceu vários homens importantes como condes, príncipes e banqueiros, que seduzidos pelo "poderio de sua carne" satisfaziam todos seus caprichos (ZOLA, 2002, p. 31). O romance parte da tese naturalista de que o homem é submetido à influência do meio e da hereditariedade. Por meio desse argumento, a história de Nana é narrada com objetivo de ficcionalizar como a protagonista é o resultado de um meio social degradante e da descendência de uma família desajustada, conforme os pressupostos teóricos da filosofia positivista, que tinha como princípio o método científico para conhecer os fenômenos naturais, individuais e sociais (ZOLA, 1979).

Antes de ser publicada em volume, a história de Nana sofreu muitas censuras na imprensa. Em carta ao diretor do Le Voltaire, Zola "disse que aceitou gostosamente alguns reparos que lhe fizeram críticos amigos, e que o romance iria aparecer em volume com as correções indicadas" (Gazeta de Notícias, 07/03/1880, p.1). 0 reparo que Zola se referia era ao desfecho dado a Nana no folhetim, que morria de varíola por tê-la contraído ao cuidar do filho doente. Tal episódio "levantou grandes clamores" (Gazeta de Notícias, 07/03/1880, p.1). No jornal Événement, o crítico Aurélien Scholl (1833-1902) declarou que "mulheres como Nana não se dedicam aos filhos, e que a ideia de Zola era um insulto feito à memória de uma senhora honestíssima, a atriz parisiense Mme. Rose Chéri (18241861)", que morreu dessa moléstia e por esse motivo (Gazeta de Notícias, 07/03/1880, p.1). Zola, para não desagradar o público leitor, alterou o final da história, pois ele queria que os leitores do folhetim comprassem o romance Nana das famosas edições Charpentier. A alteração feita pelo escritor não abrandou a indignação dos críticos. Nos jornais estrangeiros e nacionais, os críticos ainda conservavam suas opiniões contra a "escandalosa Nana" (Gazeta de Notícias, 07/03/1880, p.1).

O cronista Alberto Wolff (1835-1891), do Le Fígaro, era um dos críticos indignados. Em sua coluna, Wolff disse que ficava irritado com as excessivas "cenas despudoradas" do romance, nas quais Nana "passeava constantemente em camisa", ao ponto de "fazer-lhe mal aos nervos" (Gazeta de Notícias, 16/04/1880, p.3). 
Embora soubesse que Nana fosse um romance sobre a vida de uma prostituta, com recorrentes cenas sexuais, Wolff esperava que a "velha história" sobre as cortesãs fosse pelo menos uma "obra potente, cheia de revelações e ensinamentos", que oferecesse conhecimento à luz da Ciência. Sem entender a opção do naturalismo pela "descrição realista de todas as vergonhas", Wolff indagava-se qual importância teria para ele e, por extensão, para seus leitores "essa descrição todos os dias renovada da alcova, se não apresentava nenhum documento humano" (Gazeta de Notícias, 16/04/1880, p.3). A expectativa de encontrar "moral científica" nos romances naturalistas era a chave de leitura preferida da tradição crítica na França e no Brasil. Seguindo esse padrão de leitura, Wolff compreendia Nana como um "livro imoral", que pendia para o lado mais devasso e pornográfico do naturalismo, tornando-se numa "literatura repugnante e torpe" sobre tipos medíocres (Gazeta de Notícias, 16/04/1880, p.3).

A declaração de Wolff sobre a "inexistente moral" do naturalismo era uma opinião comum da crítica conservadora (Gazeta de Notícias, 16/04/1880, p.3). Alguns críticos, como Araripe Júnior (1848-1911), minimizavam o critério moral na apreciação dos romances naturalistas, porque eles consideravam os aspectos paradoxais e multifacetados do naturalismo, entre eles a interface da ficção naturalista com a tradição pornográfica (VIEIRA, 2015). Essa percepção também era compartilhada com os livreiros-editores, que anunciavam Nana como uma obra pornográfica, e com o público leitor, que se apropriava do romance de Zola como uma leitura libertina. Se Nana "fazia mal para os nervos" de Wolff, para outros leitores - como o Ministro da Fazenda Afonso Celso de Assis Figueiredo (1836-1912) - só fazia "alegria", conforme a nota da Gazeta de Notícias:

Dizia-se ONTEM....

...que o Sr. Afonso Celso está refazendo a saúde com os ares do Hotel Jourdan, e o espírito com o último livro de Zola, a célebre Nana...

...que S. Ex. de há muito habituado à leitura pesada dos publicistas e dos economistas, encontra um prazer especial na leitura fresca daquele romance. (Gazeta de Notícias, 21/03/1880, p1.)

A nota do jornal poderia ser um gracejo com o Ministro Afonso Celso, um dos políticos mais importante do Segundo Império do Brasil (1840-1889). Gracejo ou não, o registro da Gazeta demonstra que o romance Nana era um texto capaz de entreter, que era apropriado pelo público leitor, independente de sua classe social, como um legítimo passatempo. Segundo a Gazeta, Nana era um livro de leitura leve que restaurava o "espírito" do leitor, apesar do caráter sisudo e cientificista do naturalismo. Sendo uma derivação do folhetim, o gênero mais popular do entretenimento (MEYER, 1996), Nana apresentava a principal característica dos textos folhetinescos, a de valorizar a expectativa do leitor pelos próximos capítulos 
da história. Zola se valia das técnicas do "método científico" para explicar os "descompassos" da protagonista por meio do discurso da Ciência e, especialmente, para fomentar a ansiedade da recepção pelo final da história da célebre prostituta de Paris. O escritor alemão Paul Lindau (1839-1919) era um dos ansiosos para conhecer o destino da "atrevida Nana", embora classificasse o livro de "imoral": "é indigno [o romance], queremos rejeitar o livro, mas o interesse está acordado" (Apud BAGULEY, 1990, p.169). Interesse semelhante aos diversos leitores que compravam o romance Nana para conhecer a história e, como apontou a Gazeta, para "refazer" o bem-estar.

Em nome desse bem-estar, o comércio livreiro anunciava Nana, com a promessa de uma leitura revigorante: "boa para a saúde e ótima para os nervos", na categoria de "leitura para homens", expressão atribuída à seção dos livros pornográficos (Gazeta de Notícias, 17/06/1885, p.4). Os livreiros se fiavam na fama de escritor imoral de Zola e nas "páginas obscenas" de Nana, entre elas a nudez "pormenorizada" da protagonista, para anunciar o romance na seção mais procurada de suas livrarias (Gazeta de Notícias, 04/05/1886, p. 3). A confiança dos livreiros dava resultado, pois o "barulhento livro de Zola" atendia a demanda de um público ávido por diversões (Gazeta de Notícias 16/04/1880, p.3). 0 público era tão satisfeito com Nana que estendia o prazer da leitura para outras atividades de lazer, como as grandes corridas de cavalo no Jockey Club do Brasil, que tinha no seu plantel uma égua de puro sangue batizada com o nome da protagonista (Gazeta da Tarde, 09/05/1885, p.4). A homenagem do Jockey Club devia a uma cena magistral do romance que descrevia o "Grande Prêmio de Paris no Hipódromo de Longchamp, no Bois de Boulogne". Onde Nana exercia seu "poder carnal" sobre os distintos senhores das rodas sociais parisienses (ZOLA, 2002, p.301).

Nana foi um sucesso de vendas no Brasil oitocentista. Nas décadas de 1880 e 90, o romance era um dos títulos permanentes na seção "leitura para homens", nem as recentes publicações de "obras picantes", como os romances naturalistas $A$ carne (1888), O aborto (1893) e A mulata (1896), fizeram Nana cair no esquecimento do público (Gazeta de Notícias/RJ, 19/06/1893, p.1). 0 êxito de Nana nas livrarias - nacionais e estrangeiras - possibilitou a transposição do romance de Zola para as outras artes, como a ópera e o teatro ( $O$ Farol 03/08/1888, p.2; Diário de Pernambuco 25/04/1881, p. 8). Os leitores, em busca de diversão no "naturalismo brutal de Zola", pouco se importavam com os julgamentos dos críticos, que classificavam o livro como uma "imundície depravada" (Cearense 24/01/1884, p.2). A tarefa de censurar Nana também cabia ao espaço doméstico. Nos lares, o romance "não tinha o seu lugar nas cestinhas de costura das senhoras" e, tampouco, a "permissão das mães para que o livro fosse lido pelas filhas". (Gazeta de Notícias, 16/11/1879, p.1). Apesar das críticas e reprovações, Nana se firmava na experiência de uma leitura entusiasmada, capaz de "quebrar qualquer monotonia da vida diária" por meio das passagens repletas de "boas sensações" para o corpo e a mente dos leitores amantes das histórias de prostitutas (Gazeta da Tarde, 18/05/1896, p.1).

\section{Considerações Finais}


Nesta breve investigação sobre a trajetória de publicação, circulação e recepção dos romances Lucíola e Nana, procurei proceder à postura fundamental da perspectiva da história do livro e da leitura - a não projeção no passado de nossas maneiras de ler, pensar e sentir atualmente (CHARTIER, 1990). Segui os vestígios sobre como esses romances foram percebidos no momento de sua primeira circulação, por meio de notícias, artigos, resenhas, comentários e anúncios publicitários. Busquei considerar os modos específicos de leitura do público leitor que se apropriava de Lucíola e Nana, entre eles os livreiros-editores, críticos e leitores comuns no cenário literário brasileiro do século XIX. Essas pessoas liam esses romances cada um a sua maneira. Para os críticos conservadores, Lucíola e Nana eram obras para ser lidas como livros de lição moral, com firme propósito de "iluminar os espíritos" das moças de família para não seguir o mesmo caminho das "mulheres perdidas". A opinião dos livreiroseditores e leitores comuns sobre Lucíola e Nana passava longe da leitura moralizante da tradição crítica. Para eles, os romances sobre as "mulheres da vida" eram leituras divertidas, que "alegravam" as vendas do comércio livreiro e o ânimo dos leitores.

A identificação e a diferenciação entre as maneiras de ler dos livreiroseditores, críticos e leitores comuns demonstram que as recepções não são universais e, portanto, as especificidades dos leitores devem ser consideradas (CHARTIER, 1990). Assim como, a discriminação entre as leituras feminina e masculina. Se na sociedade patriarcal do século XIX, a leitura de Lucíola e Nana pelas moças era, de preferência, sob o olhar vigilante das mães, para os rapazes a leitura era liberada e estimulada pela grande oferta de livros pornográficos destinados (hipoteticamente) para os leitores masculinos. As antigas maneiras de ler Lucíola e Nana indicam que as apropriações dos diversos leitores dão a consciência da pluralidade dos significados dos textos e de suas variações históricas. Nesse sentido, as apropriações expõem o "ponto de entrada" para decifrar o imaginário cultural das sociedades de épocas passadas (CHARTIER, 1991, p.177). Ao entrar nesse imaginário, encontra-se a história de Lucíola e Nana como livros de entretenimento, que ofereciam leitura prazerosa por meio da ficcionalização de duas prostitutas jovens - sensuais e belas -, que provocavam as mais agradáveis sensações nos leitores. Investigar os romances Lucíola e Nana, pelo prisma da história do entretenimento, me permite testemunhar que esses livros tinham importância cultural para o público, que os buscava para restaurar seu bem-estar em meio às tensões da vida moderna no século XIX.

\section{Notas}

1 A peça e o livro expõem o aliciamento de moças de família para a prostituição por meio de homens mais velhos. No caso da peça, a exposição incomodou muito a sociedade patriarcal da época. Por ser um espetáculo teatral, As asas de um anjo escancarava as hipocrisias do patriarcalismo no palco, como a condenação das 
"mulheres perdidas". Embora a sociedade patriarcal condenasse a prostituição, na realidade, contribuía para o meretrício com homens que, em nome da moral burguesa, "procuravam" as prostitutas a fim de preservar a castidade das noivas e o sexo reprodutivo com as esposas.

\section{Referências}

ALENCAR, José de. Lucíola: um perfil de mulher. 1a Edição. Rio de Janeiro: Tipografia Francesa de Frederico Arfvedson, 1862.

Lucíola: um perfil de mulher. São Paulo: Ciranda Cultural, 2007.

BAGULEY, David. Naturalist fiction. The entropic vision. Cambridge: Cambridge University Press, 1990.

BEZERRA, Valéria Cristina. A recepção crítica de José de Alencar: a avaliação de seus romances e a representação de seus leitores. Dissertação (Mestrado em Teoria e História Literária), Universidade Estadual de Campinas, SP, 2012.

CHARTIER, Roger. A história cultural. Entre práticas e representações. Lisboa, Difel, Rio de Janeiro, Bertrand, 1990.

173-191.

O mundo como representação. Estudos Avançados, vol. XI, 1991, p.

EL FAR, Alessandra. Páginas de sensação: Literatura popular e pornográfica no Rio de Janeiro (1870-1924). São Paulo: Cia. das Letras, 2004.

MAGALHÃES JÚNIOR, Raimundo. José de Alencar e sua época. Rio de Janeiro: Civilização Brasileira; Brasília: Instituto Nacional do Livro, 1977.

MEYER, Marlyse. Folhetim: uma história. São Paulo: Cia das Letras, 1996.

SILVA, Eduardo César Ferreira da. A obra de Émile Zola no Brasil: notas para um estudo de recepção crítica. Dissertação (Mestrado em Literatura), Universidade Federal de Santa Catarina, SC,1999.

VIEIRA, Renata Ferreira. Uma penca de canalhas: Figueiredo Pimentel e o naturalismo no Brasil. 2015. 150 f. Dissertação (Mestrado em Teoria da Literatura e Literatura Comparada) - Instituto de Letras, Universidade do Estado do Rio de Janeiro, Rio de Janeiro, 2015.

ZOLA, Émile. O romance experimental e $O$ naturalismo no teatro. Trad. Ítalo Caroni e Célia Barrettini. São Paulo: Perspectiva, 1979.

. Nana. Tradução de Roberto Valeriano. Editora Nova Cultural Ltda, 2002.

Periódicos: Hemeroteca Digital Brasileira/Fundação Biblioteca Nacional: <http://memoria.bn.br/> Acesso em: 23/01/17.

Correio Paulistano, 03/05/1863, p.2

Correio Paulistano, 27/11/1863, p.2

Cearense 24/01/1884, p.2

Gazeta de Notícias, 07/03/1880, p.1

Gazeta de Notícias, 21/03/1880, p1 
Gazeta de Notícias, 16/11/1879, p.1

Gazeta de Notícias, 16/04/1880, p.3

Gazeta de Notícias, 17/06/1885, p.4

Gazeta de Notícias, 04/05/1886, p. 3

Gazeta de Notícias/RJ, 19/06/1893, p.1

Gazeta da Tarde, 02/08/1880, p.2

Gazeta da Tarde, 09/05/1885, p.4

Gazeta da Tarde, 18/05/1896, p.1

Jornal do Comércio, 26/02/1863, p.4

O País, 14/02/1883, p.1

O Farol 03/08/1888, p.2; Diário de Pernambuco 25/04/1881, p. 8

Semana Ilustrada, 17/04/1864, p.1398

\section{Para citar este artigo}

VIEIRA, Renata Ferreira. Histórias da prostituição: leituras de entretenimento no Brasil oitocentista. Macabéa - Revista Eletrônica do Netlli, Crato, v. 6, n. 2, p. 81-91, jul.-dez. 2017.

\section{Os autores}

Renata Ferreira Vieira é doutoranda do Programa de Pós-Graduação em Literatura Comparada da UERJ/CNPq. 